\title{
An Intronic Variant in OPRDI Predicts Treatment Outcome for Opioid Dependence in African-Americans
}

\author{
Richard C Crist*,', Toni-Kim Clarke', Alfonso Ang', Lisa M Ambrose-Lanci', Falk W Lohoff', \\ Andrew J Saxon ${ }^{3}$, Walter Ling ${ }^{2}$, Maureen P Hillhouse ${ }^{2}$, R Douglas Bruce ${ }^{4}$, George Woody ${ }^{5}$ and \\ Wade H Berrettini' \\ 'Center for Neurobiology and Behavior, Department of Psychiatry, University of Pennsylvania School of Medicine, Philadelphia, PA, USA; \\ 'University of California, Los Angeles, Integrated Substance Abuse Programs, Los Angeles, CA, USA; ${ }^{2}$ Veteran's Affairs Puget Sound Health Care \\ System, Seattle, WA, USA; ${ }^{4}$ Yale University School of Medicine, New Haven, CT, USA; ${ }^{5}$ Perelman School of Medicine at the University of \\ Pennsylvania, Treatment Research Institute, Philadelphia, PA, USA
}

\begin{abstract}
Although buprenorphine and methadone are both effective treatments for opioid dependence, their efficacy can vary significantly among patients. Genetic differences may explain some of the variability in treatment outcome. Understanding the interactions between genetic background and pharmacotherapy may result in more informed treatment decisions. This study is a pharmacogenetic analysis of the effects of genetic variants in OPRD I, the gene encoding the $\delta$-opioid receptor, on the prevalence of opioid-positive urine tests in African-Americans $(n=77)$ or European-Americans $(n=566)$ undergoing treatment for opioid dependence. Patients were randomly assigned to treatment with either methadone or buprenorphine/naloxone (Suboxone) over a 24-week open-label clinical trial, in which illicit opioid use was measured by weekly urinalysis. In African-Americans, the intronic SNP rs678849 predicted treatment outcome for both medications. Methadone patients with the CC genotype were less likely to have opioid-positive urine tests than those in the combined $\mathrm{CT}$ and $T \mathrm{~T}$ genotypes group (relative risk $(\mathrm{RR})=0.52$, 95\% confidence interval $(\mathrm{Cl})=0.44-0.60, p=0.00 \mathrm{I}$ ). In the buprenorphine treatment group, however, individuals with the CC genotype were more likely to have positive opioid drug screens than individuals in the combined $C T$ and $T$ genotypes group $(R R=2.17,95 \% \mathrm{Cl}=1.95-2.68, p=0.008)$. These findings indicate that the genotype at rs678849 predicts African-American patient response to two common treatments for opioid dependence, suggesting that matching patients to treatment type based on the genotype at this locus may improve overall treatment efficacy. This observation requires confirmation in an independent population.

Neuropsychopharmacology (2013) 38, 2003-2010; do: I0.1038/npp.2013.99; published online I5 May 2013
\end{abstract}

Keywords: pharmacogenetics; methadone; buprenorphine; treatment outcome.

\section{INTRODUCTION}

Opioid abuse or dependence has affected more than two million people in the United States (National Survey on Drug Use and Health, 2011). This number includes those dependent on heroin and the rapidly growing number of individuals dependent on prescription pain medications (Birnbaum et al, 2011). Opioid dependence is now the second most common cause of entry into drug treatment programs, trailing only alcoholism, and prescription opioid dependence alone accounts for an estimated $\$ 55.7$ billion in societal costs in the United States (Birnbaum et al, 2011).

\footnotetext{
*Correspondence: Dr RC Crist, Center for Neurobiology and Behavior Translational Research Laboratories, Department of Psychiatry, University of Pennsylvania School of Medicine, 125 South 31st Street, Room 2109, Philadelphia, PA 19104, USA, Tel: + I 2157463665 , Fax: + 215573 204I, E-mail: crist@mail.med.upenn.edu Received 3 December 2012; revised 5 April 2013; accepted 6 April 2013; accepted article preview online 23 April 2013
}

Methadone and buprenorphine are the two most commonly prescribed FDA-approved treatments for opioid dependence. Methadone has been in use for more than 40 years and is primarily administered as a maintenance therapy in daily oral doses in a highly regulated and specially licensed clinical setting. Buprenorphine is a newer treatment option, but has recently become more widely used because of its availability in primary care settings and more favorable safety profile (Amass et al, 1998). In the United States, buprenorphine is frequently compounded with naloxone, a parenterally active (but sublingually inactive) opioid receptor antagonist, to discourage patients from injecting the compound (Fudala et al, 1998).

A meta-analysis of clinical trials found both methadone and buprenorphine to be successful in treating opioid dependence compared with placebo (Mattick et al, 2008). Although both medications are efficacious in many individuals, a significant number of patients do not have successful treatment outcomes and illicit opioids are detected in $34-62 \%$ of urine samples collected during treatment (Fiellin et al, 2001; Johnson et al, 1995; Ling et al, 
1996; Mattick et al, 2008; Pani et al, 2000; Strain et al, 1999). Environmental factors account for some of this variation in treatment outcome. A large meta-analysis found mild-tomoderate associations between opioid use, both during and after treatment, and a variety of factors, including employment status, association with drug-using peers, stability of personal relationships, stress, and depression (Brewer et al, 1998). Although environmental factors have a substantial role in determining treatment outcome, genetic variation in the population has also been shown to alter the efficacy of medications. Variants in $A B C B 1, A N K K 1$, and DRD2 have been associated with optimal methadone dose (Crettol et al, 2006; Hung et al, 2011). ARRB2 and the cytochrome P450 genes, which encode enzymes involved in drug metabolism, have also been associated with variability in the response to methadone treatment for opioid addiction (Levran et al, 2011; Oneda et al, 2011).

The OPRD1 gene encodes the $\delta$-opioid receptor (DOR), a G-protein-coupled receptor that regulates reward effects in the brain through activation of downstream MAP kinase pathways (Herz, 1998). The opioid receptor family includes DOR, $\mu$-opioid receptor (MOR), and $\kappa$-opioid receptor (KOR), all of which have varying affinities for both endogenous and exogenous opioid peptides (reviewed in Janecka et al (2004)). Binding of opioids to either DOR or MOR results in rewarding effects, whereas activation of KOR results in stimulus aversion (Di Chiara and Imperato, 1988; Herz, 1998). DOR is also known to regulate analgesia and mood-related phenotypes in mice, and OPRD1 knockout mice have a reduced ability to develop morphine tolerance compared with wild-type mice (Filliol et al, 2000; Zhu et al, 1999).

Previous studies have associated numerous variants in OPRD1 with the risk of opioid dependence. A synonymous variant, rs2234918 (G307G), and a non-synonymous variant, rs1042114 (C27F), were found to be associated with opioid dependence in patients of European descent (Mayer et al, 1997; Zhang et al, 2008). A haplotype containing those same coding SNPs and an additional four variants (rs678849, rs2298896, rs12749204, and rs204076) was also associated with dependence on drugs, including opioids, in European-Americans (Zhang et al, 2008). Zhang et al further observed a nominal association between rs569356, a SNP that effects OPRD1 promotor activity, and opioid addiction (Zhang et al, 2010, 2008). Three common intronic SNPs (rs2236861, rs2236857, and rs3766951) were nominally associated with heroin dependence in EuropeanAmericans, although these associations were not significant after correction for multiple testing (Levran et al, 2008). In an Australian cohort, rs2236857 was again associated with heroin dependence, along with a haplotype block consisting of rs2236857 and rs581111 (Nelson et al, 2012). In addition to these associations with opioid dependence, an intronic variant of OPRD1 (rs678849) has also been associated with cocaine dependence in African-Americans (Crist et al, 2012). Despite the potential links between $O P R D 1$ variants and drug dependence, however, replication of many of these findings has been difficult (Franke et al, 1999; Loh el et al, 2004; Xuei et al, 2007). A small number of studies have also analyzed $O P R D 1$ polymorphisms in the context of addiction treatment. In one trial, the efficacy of naltrexone in treating alcoholism in European-Americans was found to be associated with the genotype at rs4654327 (Ashenhurst et al, 2012). Another study analyzed the effect of rs2234918 (G307G) on treatment outcome in opioid addicts treated with methadone; however, no association was observed (Crettol et al, 2008).

Approved treatments for opioid dependence act by affecting one or more of the opioid receptors. Methadone functions primarily as a MOR agonist (reviewed in Nicholls et al (2010)); however, downstream signaling through DOR instead of MOR has been demonstrated in mice implanted with methadone pellets for 3 days, and chronic in vitro exposure of cell lines to methadone resulted in uncoupling of DOR from the G-proteins required for downstream activation (Liu et al, 1999; Rady et al, 2002). These studies suggest that DOR may have a currently unknown role in methadone's mechanism of action. Unlike methadone, which is a full MOR agonist, buprenorphine acts as both a partial MOR agonist and a KOR antagonist (reviewed in Nicholls et al (2010)). Buprenorphine has high affinity for DOR, and some evidence suggests the medication may act as a DOR antagonist (Negus et al, 2002). Treatment with buprenorphine also results in upregulation of DOR in the rat forebrain (Belcheva et al, 1993). Despite these potential connections, the functional role of DOR following treatment with methadone or buprenorphine is unclear. A single genetic variant in OPRD1 has been studied for an effect on opioid addiction treatment, but no association was observed (Crettol et al, 2008). An open-label clinical trial, titled 'Starting Treatment with Agonist Replacement Therapy' (START), randomized opioid dependent patients to methadone or buprenorphine/naloxone (hereafter referred to as buprenorphine) to assess the effects on liver function, and also collected genetic material and data on treatment response (Saxon et al, 2013). The current study examines the associations between common OPRD1 genetic variants and treatment outcome in this clinical trial.

\section{MATERIALS AND METHODS}

\section{Participants and Procedures}

The main study methodology and primary outcomes have been previously described (Saxon et al, 2013). Briefly, individuals were recruited for treatment at federally licensed opioid treatment programs in the United States between May 2006 and October 2009. Institutional review boards at participating sites approved the study and oversight was provided by the NIDA Clinical Trials Network Data Safety and Monitoring Board. Patients met DSM-IVTR criteria for opioid dependence and were at least 18 years of age. Ethnicity was determined by self-report. Individuals were excluded from the trial for any of the following reasons: cardiomyopathy, liver disease, acute psychosis, blood levels of alanine amino transferase or aspartate amino transferase greater than five times the maximum normal level, or poor venous access. Patients were randomly assigned to 24 weeks of open-label buprenorphine or methadone treatment.

A flexible dosing approach was used, with a wide-range allowed in both induction dosing and subsequent maintenance dosing. Dose changes were allowed during the study. After an initial dose of $2-8 \mathrm{mg}$ of buprenorphine, 
first day dose could be increased to $16 \mathrm{mg}$ in the case of persistent withdrawal. Buprenorphine could be further increased in subsequent days to a maximum dose of $32 \mathrm{mg}$; the mean maximum daily dose for the trial completers analyzed in this study was $24.5 \pm 8.3 \mathrm{mg}$. The maximum initial dose of methadone was limited to $30 \mathrm{mg}$. An additional dose was allowed for persistent withdrawal up to a maximum total first day dose of $40 \mathrm{mg}$ as stipulated by US statute. Methadone could be increased in subsequent days by $10 \mathrm{mg}$ increments with no specific maximum. The mean maximum daily methadone dose for the trial completers analyzed in this study was $97.3 \pm 45.0 \mathrm{mg}$. Participants came to the clinic daily for observed dosing except on Sundays and holidays or when take-home medications were permitted by local regulations. Urine drug samples were tested weekly for opioids. Samples testing positive for methadone were counted as positive for individuals in the buprenorphine group, but not for individuals in the methadone group.

\section{SNP Selection and Genotyping}

SNPs were selected using the Tagger algorithm as part of Haploview software (http://www.broadinstitute.org/haploview) to maximize genotyping coverage in OPRD1 (Figure 1), while minimizing the total number of SNPs to genotype (Barrett et al, 2005). The region use for the Tagger program was Chromosome 1: 29 128 654-29 195 208, which includes $10 \mathrm{~kb}$ upstream and $5 \mathrm{~kb}$ downstream of the gene. Using the International HapMap Project CEU population data (HapMap data release 28 phase II and III, August 2010, http://www.hapmap.org), six SNPs (rs1042114 (C27F), rs678849, rs10753331, rs529520, rs581111, and rs2234918 (G307G)) capture $67 \%$ of SNPs in the region with a minor allele frequency cutoff of $10 \%$ and an $r^{2}$ threshold of 0.8 (Figure 1). In the HapMap ASW population data (HapMap data phase III/rel\#2 February 2009), five SNPs (rs678849, 10753331, rs529520, rs581111, and rs2234918 (G307G)) capture $18 \%$ of SNPs in the region with a minor allele frequency cutoff of $10 \%$ and an $r^{2}$ threshold of 0.8 (Figure 1). rs2234918 (G307G) was not included in the LD calculation as it was not genotyped in the HapMap population. The variant was still genotyped in this study because it is a coding variant previously associated with drug dependence (Mayer et al, 1997; Zhang et al, 2008). rs1042114 (C27F) was not genotyped in African-Americans because the SNP only has a minor allele frequency of $5.1 \%$ in that population. Of the nine variants previously found to be significantly associated with opioid addiction (either individually or as part of an associated haplotype), four variants (rs1042114, rs678849, rs581111, and rs2234918) are genotyped in this study. An additional SNP previously associated with opioid addiction (rs2298896) is tagged by rs10753331 in European-Americans, whereas rs1042114 also tags the functional promotor SNP rs569356 in that population. A comparison between the minor allele frequencies observed in this study and those in the HapMap populations is presented in Supplementary Table 1.

\section{Statistical Analysis}

For each SNP, deviation from Hardy-Weinberg Equilibrium was assessed in both the European-American and AfricanAmerican populations. All SNPs were in Hardy-Weinberg Equilibrium $(p \geqslant 0.05)$ in both populations. Because of different minor allele frequencies in the African-American and European-American populations, the two populations were analyzed separately. Initial comparisons of average outcome in methadone treatment compared with that of buprenorphine treatment were analyzed by Student's $t$-test. Linear regression was used to analyze the associations between genotype and treatment outcome, defined as the percentage of opioid-positive urine drug screens over 24 weeks, in the methadone and buprenorphine groups separately. A gene $\times$ environment analysis was performed using the percentage of opioid-positive urine drug screens over the 24 weeks of the treatment program as the phenotype, whereas treatment group was used as a covariate. All $p$-values were corrected for multiple testing using the false discovery rate procedure with the cutoff for statistical significance after correction set to $p \leqslant 0.05$ (Benjamini et al, 2001). Linear regressions, gene $\times$ environment analyses, and haplotype analyses were performed using the software package PLINK v1.07 (Purcell et al, 2007).

We used a Generalized Estimating Equation (GEE) to investigate the associations of genotype and repeated urinalysis outcomes from weeks 1 to 24 , adjusting for the effects of time, age, gender, maximal dose, and treatment group. A second GEE analysis was performed with cocaine dependence status included as an additional covariate. GEE is a quasi-likelihood-based method, which produces population averaged estimates for repeated binary outcomes (Liang and Zeger, 1986). We report our estimates as relative risks (RRs), and bootstrapped 95\% confidence intervals (CIs) based on 1000 replicate samples. Because of the small number of African-American patients with the $\mathrm{T} / \mathrm{T}$ genotype $(n=3)$, individuals with the T/T genotype

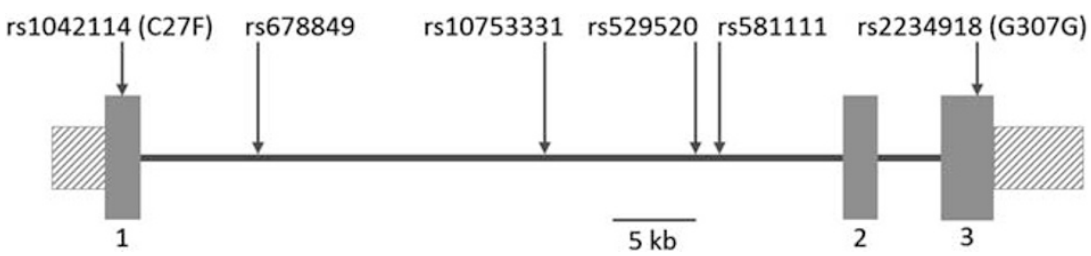

Figure I Diagram of the OPRD / gene (Chrl: 29/38654-29190208) and the six SNPs genotyped in this study. Gray boxes indicate exons and boxes with diagonal lines indicate untranslated regions. The residue numbers and encoded amino acids of the synonymous and non-synonymous variants are included after the SNP IDs. SNP and exon locations taken from the February 2009 build of the human genome in UCSC Genome Browser (http://www.genome.ucsc.edu). 
were combined with those with the C/T genotype in all analyses of that ethnic group. We analyzed urinalysis outcomes for both treatment groups separately and for the entire sample as a whole, examining the main effects of treatment and $\mathrm{C} / \mathrm{C}$ genotype, as well as the interaction effect of treatment $\times \mathrm{C} / \mathrm{C}$ genotype. Urine drug screens missed by patients were excluded from all analyses.

\section{RESULTS}

\section{Demographics}

DNA samples were available from 566 European-Americans and 77 African-Americans who received either methadone or buprenorphine for the treatment of opioid dependence. The mean age, gender percentages, and average outcome for the two treatment groups are provided in Table 1 for both European-Americans and African-Americans. The average percentage of opioid-positive urine tests was not significantly different between patients administered methadone $(38.6 \%)$ or buprenorphine $(36.6 \%, p=0.47)$. African-Americans had significantly more opioid-positive urine tests than European-Americans when treated with either methadone (AA: $51.7 \pm 34.3 \%$, EA: $36.9 \pm 32.9 \%$, $p=0.02$ ) or buprenorphine (AA: $48.3 \pm 38.2 \%$, EA: $34.9 \pm 36.9 \%, p=0.02)$.

\section{Genotyping Results}

The locations of the genotyped SNPs are indicated on a map of the OPRD1 gene (Figure 1). To ensure that the randomization process in the clinical trial had not skewed the allele frequencies in either of the treatment groups, the minor allele frequencies in the methadone and buprenorphine groups were compared. The minor allele frequencies for all variants were not significantly different between the two treatment groups in either European-Americans or African-Americans (data not shown).

\section{Pharmacogenetic Analyses}

Linear regression was used to determine if any of the genotyped variants were associated with the percentage of opioid-positive urine tests over the 24-week trial in either the methadone or buprenorphine groups. No significant associations were found in European-Americans (Table 2); however, a single variant, rs678849, was significantly associated with treatment outcome in African-Americans prescribed buprenorphine (Table 3). In the African-American group treated with buprenorphine, individuals with the CC genotype at rs678849 had significantly more positive opioid urine test results during 24 weeks of treatment $(60.7 \pm 37.2 \%)$ than individuals in the combined CT and TT genotypes group $(30.7 \pm 32.3 \%, p=0.004$; Table 3$)$. This effect was not observed in the African-American methadone treatment group (CC genotype: $42.7 \pm 30.0 \%$; CT/TT genotypes: $64.2 \pm 36.1 \%, p=0.07$; Table 3 ). Haplotype analysis was used to determine if multiple SNPs were significantly associated with outcome in either treatment group. Nominally significant haplotypes were identified in the European-American and African-American populations for both treatments, however, none of these haplotypes were significant after correction for multiple testing (Supplementary Table 2). In African-Americans treated with buprenorphine, none of the haplotypes were more informative than rs678849 alone.

To further determine if the selected $O P R D 1$ variants were associated with outcome when comparing methadone with buprenorphine, a gene $\times$ environment analysis was performed with treatment group as the environmental covariate. The percentage of opioid-positive urine tests over the 24-week trial was used as the measure of treatment outcome. Although there were no significant interactions observed in European-Americans (Table 2), there was a significant association between the genotype at rs678849 and treatment outcome in African-Americans $(p=0.0008$; Table 3). GEEs were used to calculate the effect of this gene $\times$ environment interaction when the 24 weeks of urinalysis data were taken as repeated measures. A significant interaction between the genotype at rs678849 and treatment group was again observed in AfricanAmericans $\left(\mathrm{RR}=3.26,95 \% \mathrm{CI}=2.66-4.19, p=5.9 \times 10^{-5}\right)$. As expected, buprenorphine patients with the CC genotype were more likely to have opioid-positive drug screens than individuals in the combined CT and TT genotypes group $(\mathrm{RR}=2.17,95 \% \mathrm{CI}=1.95-2.68, p=0.008) \quad$ (Figure $2 \mathrm{~b})$. Methadone patients with the CC genotype, however, were less likely to have opioid-positive urine drug screens than those in the combined CT and TT genotypes group $(\mathrm{RR}=0.52,95 \% \mathrm{CI}=0.44-0.60, p=0.001$; Figure $2 \mathrm{a})$. No effects of age, gender, or maximal dose were observed. As rs678849 has been previously associated with cocaine dependence in African-Americans, the data were reanalyzed with cocaine dependence status as a covariate. Cocaine dependence was not significantly associated with opioid-positive drug urine drug screens, whereas the

Table I Demographic Information and Treatment Outcomes for Patients Treated with Methadone or Buprenorphine for Opioid Dependence

\begin{tabular}{|c|c|c|c|c|}
\hline $\begin{array}{l}\text { Treatment group } \\
\text { Ethnicity }\end{array}$ & $\begin{array}{c}\text { Methadone } \\
\text { EA }\end{array}$ & $\begin{array}{c}\text { Methadone } \\
\text { AA }\end{array}$ & $\begin{array}{c}\text { Buprenorphine } \\
\text { EA }\end{array}$ & $\begin{array}{c}\text { Buprenorphine } \\
\text { AA }\end{array}$ \\
\hline Number (\% male) & 275 (63.3\%) & $36(72.2 \%)$ & $29 \mid(72.5 \%)$ & $4 \mid(65.9 \%)$ \\
\hline Mean maximal dose $\pm \mathrm{SD}$ (mg) & $99.7 \pm 46.4$ & $79.2 \pm 26.5$ & $24.8 \pm 8.4$ & $22.5 \pm 6.9$ \\
\hline Mean \% opioid positive Urinalysis \pm SD & $36.9 \pm 32.9 \%$ & $51.7 \pm 34.3 \%$ & $34.9 \pm 36.9 \%$ & $48.3 \pm 38.2 \%$ \\
\hline
\end{tabular}

Abbreviations: AA, African-American; EA, European-American. 
Table 2 Analysis of Associations Between OPRD / Genetic Variants and Treatment Outcome in Opioid-dependent European-Americans

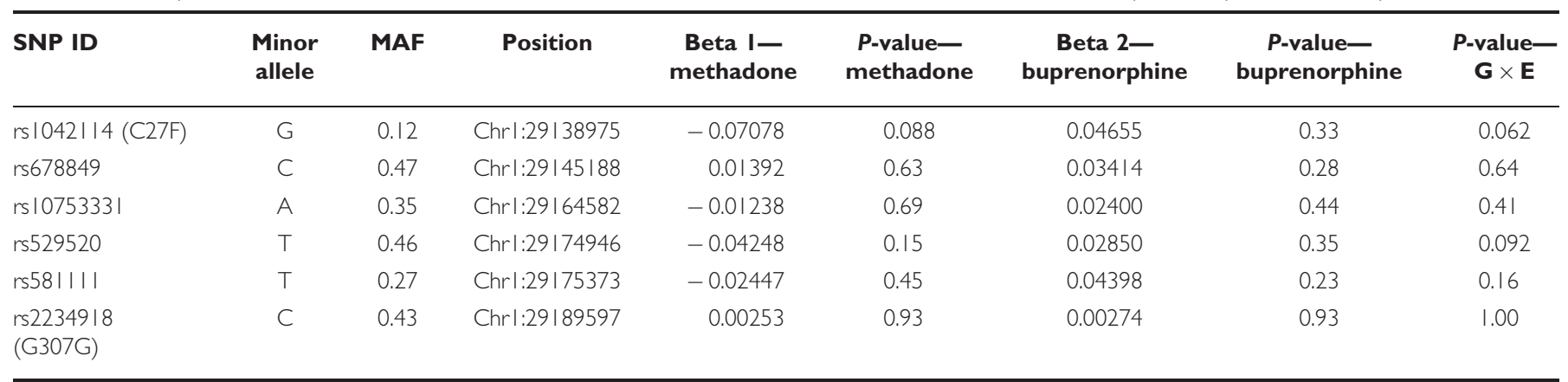

Abbreviations: $\mathrm{G} \times \mathrm{E}$, gene $\times$ environment; MAF, minor allele frequency.

$P$-values were generated by linear regression for the individual treatment groups, as well as gene $\times$ environment analyses with treatment group as a covariate.

The residue numbers and encoded amino acids of the synonymous and non-synonymous variants are included after the SNP IDs.

Table 3 Analysis of Associations Between OPRD / Genetic Variants and Treatment Outcome in Opioid-dependent African-Americans

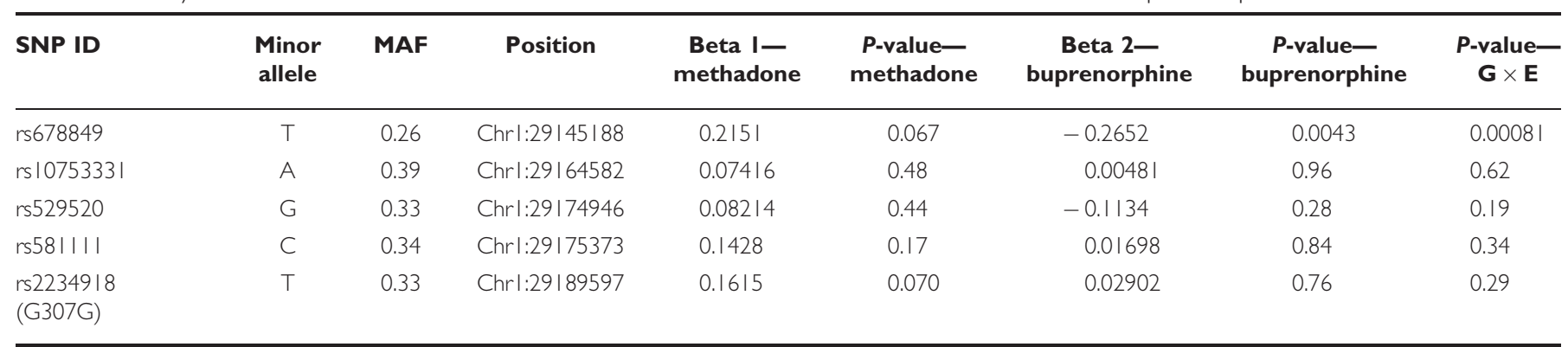

Abbreviations: $\mathrm{G} \times \mathrm{E}$, gene $\times$ environment; MAF, minor allele frequency.

P-values were generated by linear regression for the individual treatment groups, as well as gene $x$ environment analyses with treatment group as a covariate.

The residue number and encoded amino acids of the synonymous variant is included after the SNP ID.
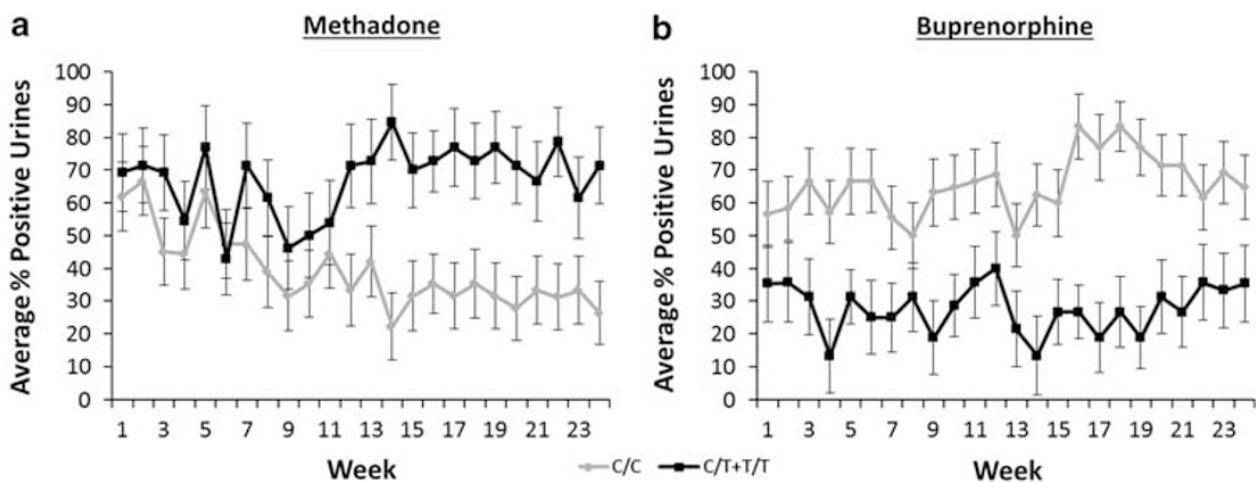

Figure 2 Weekly urinalysis data for African-Americans based on rs678849 genotype. Patients were treated for opioid dependence with either methadone (a) or buprenorphine (b) for 24 weeks. Weekly urine drug screens were administered for the presence of opioids other than the one prescribed. The average percentage of opioid-positive urine tests during each week is provided for individuals with either the $\mathrm{C} / \mathrm{C}$ genotype or the $\mathrm{C} / \mathrm{T}$ and T/T genotypes, which were combined due to the low number of T/T patients $(n=3)$. Time, age, gender, maximal dose, and treatment group were analyzed as covariates. (a) Methadone patients with the $C C$ genotype $(n=21)$ were less likely to have opioid-positive urine drug screens than patients with the $C / T$ or $\mathrm{T} / \mathrm{T}$ genotypes $(n=15 ; \mathrm{RR}=0.52,95 \% \mathrm{Cl}=0.44-0.60, p=0.00 \mathrm{I})$. (b) Buprenorphine patients with the CC genotype $(n=24)$ were more likely to have opioid-positive drug screens than patients with the $\mathrm{C} / \mathrm{T}$ or $\mathrm{T} / \mathrm{T}$ genotypes $(n=17 ; \mathrm{RR}=2.17,95 \% \mathrm{Cl}=1.95-2.68, p=0.008)$.

interaction between rs678849 genotype and treatment group was still significant $(\mathrm{RR}=3.46,95 \% \mathrm{CI}=2.28-4.40$, $\left.p=3.4 \times 10^{-5}\right)$.

\section{DISCUSSION}

The present pharmacogenetic study describes the associations between common OPRD1 genetic variants and patient outcome in two treatments for opioid dependence. No significant associations were observed in European-Americans, whereas one variant (rs678849) was associated with treatment outcome in African-Americans. AfricanAmerican patients with the CC genotype had significantly more illicit opioid use when treated with buprenorphine compared with patients in the combined CT and TT genotypes group. Conversely, African-American patients 
with the CC genotype had significantly worse opioid use outcomes when treated with methadone than individuals in the combined CT and TT genotypes group. These associations were independent of age, gender, maximal dose, or cocaine dependence status.

The opposite associations between rs678849 genotype and treatment outcome in the methadone and buprenorphine groups may reflect the different mechanisms of action of the two drugs. Methadone is classified as a MOR agonist, reducing illicit opioid use through MOR activation that minimizes withdrawal symptoms and moderates craving. Extended methadone treatment, however, may have offtarget effects on DOR as well as suggested by several recent studies. Patients undergoing methadone maintenance, for example, show decreased levels of DOR protein in lymphocytes, and cell lines treated with methadone have shown similar decreases in expression (Toskulkao et al, 2010). Other in vitro studies have indicated that methadone treatment results in uncoupling of DOR from G-proteins, leading to desensitization of DOR (Liu et al, 1999). Methadone may also activate signaling through DOR. Methadone-induced antinociception is caused by signaling through MOR in both mice and rats; however, administration of methadone for several days results in a switch to DOR signaling (Morinville et al, 2003; Rady et al, 2002). Methadone has also been shown to have higher efficacy at MOR/DOR heterodimers than at MOR monomers (Yekkirala et al, 2012).

Unlike methadone, buprenorphine is a partial MOR agonist that also functions as a KOR antagonist. In addition, buprenorphine has high affinity for DOR (Negus et al, 2002; Wood et al, 1981). The medication appears to have limited ability to activate downstream signaling through DOR, although some evidence suggests that norbuprenorphine, a metabolite of buprenorphine, functions as a DOR agonist in vitro (Huang et al, 2001; Kajiwara et al, 1986). Other data suggest that buprenorphine is instead an antagonist of the DOR protein (Negus et al, 2002). Buprenorphine treatment has also been shown to induce upregulation of DOR in the mouse forebrain (Belcheva et al, 1993). The functional relevance of this increased receptor expression is unclear. The connections between DOR and both methadone and buprenorphine suggest that DOR may be more relevant to the mechanisms of action of these medications than currently believed.

The association between rs678849 and treatment outcome indicates that rs678849 tags the locus responsible for the observed effect or is itself the causative SNP. Based on data from the 1000 Genomes Project, rs678849 is not in high LD $\left(r^{2}>0.7\right)$ with any other SNP in OPRD1. Given the minor allele frequency of rs678849 in African-Americans (25.5\%), it is unlikely that sequencing projects such as the 1000 Genomes Project have overlooked a tagged variant of similar frequency. There are also no known copy number variations (Database of Genomic Variants, http://projects. tcag.ca/variation) or microRNAs (UCSC Genome Browser, http://www.genome.ucsc.edu) in the vicinity of OPRD1 in African-Americans, leaving rs678849 as a good candidate for the causative variant in this study. As an intronic SNP more than $6 \mathrm{~kb}$ from the nearest exon, it is unclear what effect rs678849 might have on the OPRD1 transcript. The SNP does not affect a CpG site that could potentially be methylated, nor does it reside within any predicted $\mathrm{CpG}$ islands (UCSC Genome Browser). However, the SNP could still potentially affect splicing of the OPRD1 transcript, or change expression of OPRD1 by altering transcription factorbinding sites. The TRANSFAC database predicts the $\mathrm{T}$ allele of rs678849 to contribute to a binding site for the transcription factor USF2; however, this binding site is not predicted in the presence of the $\mathrm{C}$ allele. There is also a possibility that the observed effects of rs678849 involve genes other than OPRD1. For example, the SNP is identified as an expression-QTL for PHACTR4 (http://eqtl.uchicago.edu), which encodes a neuronally expressed regulator of protein phosphatase 1 (Montgomery et al, 2010; Zhang et al, 2012). However, the gene is located more than $300 \mathrm{~kb}$ upstream of rs678849 and regulation by the variant would necessitate the existence of a long-range enhancer. Another explanation is that rs678849 is not the causative SNP, but is instead in highlinkage disequilibrium with multiple less common variants that all have effects on the efficacy of methadone and buprenorphine. Although the mechanism of rs678849 is unclear, this study is not the first association observed between the variant and addiction-related phenotypes. The major allele of rs678849 (C) has been found to be associated with cocaine dependence in African-Americans and a six SNP haplotypes including the C allele of rs678849 was associated with alcohol, cocaine, and opioid dependence in European-Americans (Crist et al, 2012; Zhang et al, 2008). These studies further support the role of rs678849 in drug addiction phenotypes.

One important clinical question arising from these data is why the effect of rs678849 is only observed in AfricanAmericans. Differences in the response to exogenous opioids between ancestral populations have previously been observed (Bayerer et al, 2007; Nielsen et al, 2010). The effect of butorphanol and morphine on certain types of analgesia is greater in African-Americans compared with nonHispanic whites (Sibille et al, 2011). The different genetic backgrounds of African-Americans and European-Americans are likely to contribute to the differential response to opioids observed by Sibille et al (2011). Drug metabolism rates between patients of different ancestry have also been associated with genetic variation (Bradford, 2002). Polymorphisms in the genes encoding enzymes that metabolize medications may alter the response to methadone or buprenorphine and occur at different frequencies across various ethnic groups, suggesting a potential mechanism by which genetic background might modify the effect of rs678849 on treatment outcome in a population-specific manner.

The association of rs678849 genotype with both methadone and buprenorphine treatment outcome suggests that patient genotype may be valuable information when selecting between treatment options; however, there are several potential limitations with this analysis. During the START clinical trial, an increased dropout rate and subsequent increase in missed urine drug tests was observed in patients treated with buprenorphine $(25.4 \%$ missed tests) compared with those treated with methadone (12.9\%; Saxon et al, 2013). As our analyses excluded these missing tests, opioid usage rates may be higher than those calculated from our urinalysis data, particularly in buprenorphine patients. In addition, less than $12 \%$ of the patients 
enrolled in the START clinical trial self-reported their ethnicity as African-American. This low percentage is consistent with many other clinical trials for opioid dependence in the United States, in which the most common ethnicity among patients is European-American (Fiellin et al, 2001; Johnson et al, 1995; Ling et al, 1996; Strain et al, 1999; Woody et al, 2008). The relatively small number of African-American patients in this study increases the possibility that the study population is not an accurate representation of the opioid-addicted AfricanAmerican population as a whole. Because of these limitations, replication of our study in an independent population of opioid-dependent African-Americans will be required. Unfortunately, few relevant sample sets are currently available. As mentioned above, the majority of patients in opioid cessation clinical trials are European-American. Although African-Americans are the next largest ethnic group enrolled in these trials, they often account for less than $25 \%$ of total samples (Fiellin et al, 2001; Johnson et al, 1995; Ling et al, 1996; Strain et al, 1999; Woody et al, 2008). Many previous studies would, therefore, be underpowered for a retrospective pharmacogenetic study of AfricanAmericans because of small sample sizes. As our findings indicate a pharmacogenetic effect with potential clinical relevance for the treatment of opioid dependence, confirmation through either a retrospective or prospective clinical trial must be a priority.

\section{FUNDING AND DISCLOSURE}

Falk Lohoff received research grant support from Pfizer. Issued to University of Pennsylvania and also scientific advisor or paid consultant to Pamlab. Guidepoint Global LLC, Genome Canada, and Genome Quebec. Andrew Saxon is a paid consultant to Reckitt Benckiser Pharmaceuticals; Walter Ling is a paid consultant to Reckitt Benckiser Pharmaceuticals; R Douglas Bruce received research grant support from Gilead Sciences, Merck \& Co., Bristol Myers Squibb, Boehringer Ingelheim, Reckitt Benckiser Pharmaceuticals, Abbott Laboratories, Pfizer, Inc., and honorarium from Reckitt Benckiser Pharmaceuticals; the remaining authors declare no conflict of interest.

\section{ACKNOWLEDGEMENTS}

Main START study funding came from the National Institute on Drug Abuse through the Clinical Trials Network (CTN) through a series of grants provided to each participating node: the Pacific Northwest Node (U10 DA01714), the Oregon Hawaii Node (U10 DA013036), the California/ Arizona Node (U10 DA015815), the New England Node (U10 DA13038), the Delaware Valley Node (U10 DA13043), the Pacific Region Node (U10 DA13045), and the New York Node (U10 DA013046). Dr Berrettini was also supported by the Delaware Valley Node (U10 DA13043). This work was supported by the Center for Neurobiology and Behavior, Department of Psychiatry, University of Pennsylvania, Training Program in Neuropsychopharmacology (T32MH014654, P.I.: I. Lucki), NIDA grant P20DA025995 (P.I.: W. Berrettini), the Veterans Administration Mental Illness Research Education and Clinical Center MIRECC) at the Philadelphia VAMC (David Oslin, MD, PI) and NIDA grant P60DA05186 (P.I.: Charles O’Brien).

\section{REFERENCES}

Amass L, Bickel WK, Crean JP, Blake J, Higgins ST (1998). Alternateday buprenorphine dosing is preferred to daily dosing by opioiddependent humans. Psychopharmacology (Berl) 136: 217-225.

Ashenhurst JR, Bujarski S, Ray LA (2012). Delta and kappa opioid receptor polymorphisms influence the effects of naltrexone on subjective responses to alcohol. Pharmacol Biochem Behav 103: 253-259.

Barrett JC, Fry B, Maller J, Daly MJ (2005). Haploview: analysis and visualization of LD and haplotype maps. Bioinformatics (Oxford, England) 21: 263-265.

Bayerer B, Stamer U, Hoeft A, Stuber F (2007). Genomic variations and transcriptional regulation of the human mu-opioid receptor gene. Eur J Pain 11: 421-427.

Belcheva MM, Barg J, McHale RJ, Dawn S, Ho MT, Ignatova E et al (1993). Differential down- and up-regulation of rat brain opioid receptor types and subtypes by buprenorphine. Mol Pharmacol 44: 173-179.

Benjamini Y, Drai D, Elmer G, Kafkafi N, Golani I (2001). Controlling the false discovery rate in behavior genetics research. Behav Brain Res 125: 279-284.

Birnbaum HG, White AG, Schiller M, Waldman T, Cleveland JM, Roland CL (2011). Societal costs of prescription opioid abuse, dependence, and misuse in the United States. Pain Med 12: 657-667.

Bradford LD (2002). CYP2D6 allele frequency in European Caucasians, Asians, Africans and their descendants. Pharmacogenomics 3: 229-243.

Brewer DD, Catalano RF, Haggerty K, Gainey RR, Fleming CB (1998). A meta-analysis of predictors of continued drug use during and after treatment for opiate addiction. Addiction 93: 73-92.

Crettol S, Besson J, Croquette-Krokar M, Hammig R, Gothuey I, Monnat $\mathrm{M}$ et al (2008). Association of dopamine and opioid receptor genetic polymorphisms with response to methadone maintenance treatment. Prog Neuropsychopharmacol Biol Psychiatry 32: 1722-1727.

Crettol S, Deglon JJ, Besson J, Croquette-Krokar M, Hammig R, Gothuey I et al (2006). ABCB1 and cytochrome P450 genotypes and phenotypes: influence on methadone plasma levels and response to treatment. Clin Pharmacol Ther 80: 668-681.

Crist RC, Ambrose-Lanci LM, Vaswani M, Clarke TK, Zeng A, Yuan C et al (2012). Case-control association analysis of polymorphisms in the delta-opioid receptor, OPRD1, with cocaine and opioid addicted populations. Drug Alcohol Depend 127: 122-128.

Di Chiara G, Imperato A (1988). Opposite effects of mu and kappa opiate agonists on dopamine release in the nucleus accumbens and in the dorsal caudate of freely moving rats. J Pharmacol Exp Ther 244: 1067-1080.

Fiellin DA, O'Connor PG, Chawarski M, Pakes JP, Pantalon MV, Schottenfeld RS (2001). Methadone maintenance in primary care: a randomized controlled trial. JAMA 286: 1724-1731.

Filliol D, Ghozland S, Chluba J, Martin M, Matthes HW, Simonin F et al (2000). Mice deficient for delta- and mu-opioid receptors exhibit opposing alterations of emotional responses. Nat Genet 25: $195-200$.

Franke P, Nothen MM, Wang T, Neidt H, Knapp M, Lichtermann D et al (1999). Human delta-opioid receptor gene and susceptibility to heroin and alcohol dependence. Am J Med Genet 88: 462-464.

Fudala PJ, Yu E, Macfadden W, Boardman C, Chiang CN (1998). Effects of buprenorphine and naloxone in morphine-stabilized opioid addicts. Drug Alcohol Depend 50: 1-8.

Herz A (1998). Opioid reward mechanisms: a key role in drug abuse? Can J Physiol Pharmacol 76: 252-258. 
Huang P, Kehner GB, Cowan A, Liu-Chen LY (2001). Comparison of pharmacological activities of buprenorphine and norbuprenorphine: norbuprenorphine is a potent opioid agonist. J Pharmacol Exp Ther 297: 688-695.

Hung CC, Chiou MH, Huang BH, Hsieh YW, Hsieh TJ, Huang CL et al (2011). Impact of genetic polymorphisms in ABCB1, CYP2B6, OPRM1, ANKK1 and DRD2 genes on methadone therapy in Han Chinese patients. Pharmacogenomics 12: 1525-1533.

Janecka A, Fichna J, Janecki T (2004). Opioid receptors and their ligands. Curr Top Med Chem 4: 1-17.

Johnson RE, Eissenberg T, Stitzer ML, Strain EC, Liebson IA, Bigelow GE (1995). Buprenorphine treatment of opioid dependence: clinical trial of daily versus alternate-day dosing. Drug Alcohol Depend 40: 27-35.

Kajiwara M, Aoki K, Ishii K, Numata H, Matsumiya T, Oka T (1986). Agonist and antagonist actions of buprenorphine on three types of opioid receptor in isolated preparations. Jpn J Pharmacol 40: 95-101.

Levran O, Londono D, O'Hara K, Nielsen DA, Peles E, Rotrosen J et al (2008). Genetic susceptibility to heroin addiction: a candidate gene association study. Genes Brain Behav 7: 720-729.

Levran O, Peles E, Hamon S, Randesi M, Adelson M, Kreek MJ (2011). CYP2B6 SNPs are associated with methadone dose required for effective treatment of opioid addiction. Addict Biol; e-pub ahead of print. doi:10.1111/j.1369-1600.2011.00349.x.

Liang KYZ, Zeger SL (1986). Longitudinal data analysis using generalized linear models. Biometrika 73: 13-22.

Ling W, Wesson DR, Charuvastra C, Klett CJ (1996). A controlled trial comparing buprenorphine and methadone maintenance in opioid dependence. Arch Gen Psychiatry 53: 401-407.

Liu JG, Liao XP, Gong ZH, Qin BY (1999). Methadone-induced desensitization of the delta-opioid receptor is mediated by uncoupling of receptor from G protein. Eur J Pharmacol 374: 301-308.

Loh el W, Fann CS, Chang YT, Chang CJ, Cheng AT (2004). Endogenous opioid receptor genes and alcohol dependence among Taiwanese Han. Alcohol Clin Exp Res 28: 15-19.

Mattick RP, Kimber J, Breen C, Davoli M (2008). Buprenorphine maintenance versus placebo or methadone maintenance for opioid dependence. Cochrane Database Syst Rev(2): CD002207.

Mayer P, Rochlitz H, Rauch E, Rommelspacher H, Hasse HE, Schmidt S et al (1997). Association between a delta opioid receptor gene polymorphism and heroin dependence in man. Neuroreport 8: 2547-2550.

Montgomery SB, Sammeth M, Gutierrez-Arcelus M, Lach RP, Ingle $C$, Nisbett $J$ et al (2010). Transcriptome genetics using second generation sequencing in a Caucasian population. Nature 464: 773-777.

Morinville A, Cahill CM, Esdaile MJ, Aibak H, Collier B, Kieffer BL et al (2003). Regulation of delta-opioid receptor trafficking via mu-opioid receptor stimulation: evidence from mu-opioid receptor knock-out mice. J Neurosci 23: 4888-4898.

Negus SS, Bidlack JM, Mello NK, Furness MS, Rice KC, Brandt MR (2002). Delta opioid antagonist effects of buprenorphine in rhesus monkeys. Behav Pharmacol 13: 557-570.

Nelson EC, Lynskey MT, Heath AC, Wray N, Agrawal A, Shand FL et al (2012). Association of OPRD1 polymorphisms with heroin dependence in a large case-control series. Addict Biol; e-pub ahead of print. doi:10.1111/j.1369-1600.2012.00445.x.

Nicholls L, Bragaw L, Ruetsch C (2010). Opioid dependence treatment and guidelines. J Manag Care Pharm 16(1 Suppl B): S14-S21.

Nielsen DA, Ji F, Yuferov V, Ho A, He C, Ott J et al (2010). Genome-wide association study identifies genes that may contribute to risk for developing heroin addiction. Psychiatric Genet 20: 207-214.
Oneda B, Crettol S, Bochud M, Besson J, Croquette-Krokar M, Hammig $\mathrm{R}$ et al (2011). Beta-arrestin2 influences the response to methadone in opioid-dependent patients. Pharmacogenomics J 11: 258-266.

Pani PP, Maremmani I, Pirastu R, Tagliamonte A, Gessa GL (2000). Buprenorphine: a controlled clinical trial in the treatment of opioid dependence. Drug Alcohol Depend 60: 39-50.

Purcell S, Neale B, Todd-Brown K, Thomas L, Ferreira MA, Bender D et al (2007). PLINK: a tool set for whole-genome association and population-based linkage analyses. Am J Hum Genet 81: 559-575.

Rady JJ, Portoghese PS, Fujimo JM (2002). Methadone and heroin antinociception: predominant delta-opioid-receptor responses in methadone-tolerant mice. Jpn J Pharmacol 88: 319-331.

Saxon AJ, Ling W, Hillhouse M, Thomas C, Hasson A, Ang A et al (2013). Buprenorphine/Naloxone and methadone effects on laboratory indices of liver health: A randomized trial. Drug Alcohol Depend 128: 71-76.

Sibille KT, Kindler LL, Glover TL, Gonzalez RD, Staud R, Riley JL 3 rd et al (2011). Individual differences in morphine and butorphanol analgesia: a laboratory pain study. Pain Med 12: 1076-1085.

Strain EC, Bigelow GE, Liebson IA, Stitzer ML (1999). Moderate- vs high-dose methadone in the treatment of opioid dependence: a randomized trial. JAMA 281: 1000-1005.

Substance Abuse and Mental Health Services Administration, Results from the 2010 National Survey on Drug Use and Health: Summary of National Findings, NSDUH Series H-41, HHS Publication No. (SMA) 11-4658. Rockville, MD: Substance Abuse and Mental Health Services Administration, 2011.

Toskulkao T, Pornchai R, Akkarapatumwong V, Vatanatunyakum S, Govitrapong P (2010). Alteration of lymphocyte opioid receptors in methadone maintenance subjects. Neurochem Int 56: 285-290.

Wood PL, Charleson SE, Lane D, Hudgin RL (1981). Multiple opiate receptors: differential binding of mu, kappa and delta agonists. Neuropharmacology 20: 1215-1220.

Woody GE, Poole SA, Subramaniam G, Dugosh K, Bogenschutz M, Abbott $\mathrm{P}$ et al (2008). Extended vs short-term buprenorphinenaloxone for treatment of opioid-addicted youth: a randomized trial. JAMA 300: 2003-2011.

Xuei X, Flury-Wetherill L, Bierut L, Dick D, Nurnberger J Jr, Foroud $\mathrm{T}$ et al (2007). The opioid system in alcohol and drug dependence: family-based association study. Am J Med Genet B Neuropsychiatr Genet 144B: 877-884.

Yekkirala AS, Banks ML, Lunzer MM, Negus SS, Rice KC, Portoghese PS (2012). Clinically employed opioid analgesics produce antinociception via $\mu-\delta$ opioid receptor heteromers in Rhesus monkeys. ACS Chem Neurosci 3: 720-727.

Zhang H, Gelernter J, Gruen JR, Kranzler HR, Herman AI, Simen AA (2010). Functional impact of a single-nucleotide polymorphism in the OPRD1 promoter region. J Hum Genet 55: 278-284.

Zhang H, Kranzler HR, Yang BZ, Luo X, Gelernter J (2008). The OPRD1 and OPRK1 loci in alcohol or drug dependence: OPRD1 variation modulates substance dependence risk. Mol Psychiatry 13: $531-543$

Zhang Y, Kim TH, Niswander L (2012). Phactr4 regulates directional migration of enteric neural crest through PP1, integrin signaling, and cofilin activity. Genes Dev 26: 69-81.

Zhu Y, King MA, Schuller AG, Nitsche JF, Reidl M, Elde RP et al (1999). Retention of supraspinal delta-like analgesia and loss of morphine tolerance in delta opioid receptor knockout mice. Neuron 24: 243-252.

Supplementary Information accompanies the paper on the Neuropsychopharmacology website (http://www.nature.com/npp) 